\title{
Simulation and Hardware Implementation of MPPT Based Single Phase Photovoltaic Inverter Using TMS320C28027 Control
}

\author{
Prashant. V. Thakre and Saroj. Rangnekar
}

\begin{abstract}
-to harness the solar energy, various energy conversion technologies are required. Photovoltaic $(\mathrm{PV})$ panels, or commonly known as solar panels, are devices used to convert sunlight into electricity. The acronym PV stands for photo (light) and voltaic (electricity), whereby sunlight photons free electrons from the atoms of the panels and creates a voltage difference. Since the PV panels convert sunlight into electricity in the form of direct current (dc), while most electrical devices for residential applications require alternating current (ac), dc-ac power conversion is needed. This can be realized by power converter known as inverter. In solar energy systems, PV inverter is the power converter used specifically to convert the dc power obtained from $\mathrm{PV}$ panels into ac power. From the economic point of view, although the cost of $P V$ power is relatively high as compared to other renewable energy sources such as wind and biomass, it has decreased from more than $\$ 50 / W$ in the early 1980 s to about $\$ 5 / W$ today. Besides, the $P V$ panels can be designed as part of the roof structure, replacing the conventional ceramic or concrete-based roof tiles. In view of these advantages, PV is envisaged as a viable economics proposition of the future. As the solar energy for residential application is gaining considerable interest, there have been numerous PV inverter topologies proposed in the literature. PV grid connected and stand alone systems are becoming more and more popular now a days. With proper tracking system an efficient inverter system can be developed for single phase as well as three phase. This research paper is basically based on the approach that by considering a conventional tracking system a single phase inverter circuit is implemented whose switching is done by using DSP TMS320C28027.
\end{abstract}

Index Terms-Photovoltaic panels, boost converter, bridge inverter, unipolar pwm switching, TMS320C28027.

\section{INTRODUCTION}

With the increasing concern about the non-renewable energy sources, constant increase in the prices of fossil fuels, global warming and damage to environment and ecosystem, the renewable energy is becoming more popular and is gaining more attention as an alternative to non-renewable energy sources. Among the renewable energy sources, the energy through photovoltaic effect is being considered as the most essential and sustainable energy resource such as compared to other type of energy sources such as wind, biomass, hydro power, tidal.

Nowadays photovoltaic system are likely recognized \& widely utilized for different types of power system

Manscript received April 6, 2011; revised July 6, 2011.This work is supported by Energy Centre, MANIT, and Bhopal. applications. These systems can generate direct current electricity without any environmental impact. Being a semiconductor device, the PV system is static and free of moving parts which make it easy for operation and also requires less maintenance. As per A. Yafaoui., B. Wu and R. Cheung [3] there are number of methods by which a photovoltaic modules can be arrange for harvesting the solar energy such as perturb and observe method, open and short circuit method and estimate perturb-perturb method for maximum power point tracking.

Thus the extracted signal from a photovoltaic array can be used directly or it can be stored depending upon the type of system used. For an inverter application if used in stand alone mode, it operates independently of the grid without battery storage. For domestic purpose it is desired that the inverter be able to operate in both mode of operation.

The main contribution of this paper is based on conventional tracking system based performance and analysis of a bidirectional frequency link photovoltaic inverter using texas piccolo series processor TMS320C28027.

As per Tames Kerkes, Dezso Sera and Rimes Toe [2] a dsp processor TMS320F2812 can be efficiently used for power control in an inverter circuit. Also as per Hao Zhou,Chawan Tong,Meiqin Mao,Chan Gao [6] TMS320F28335 can also be efficiently used for generating switching signals for inverter application.

This research paper mainly concentrates on stand alone system with a solar tracker connected to a bidirectional high frequency link inverter circuit. This inverter circuit is controlled by considering Texas piccolo series processor TMS320C28027 which is more advanced, specific and cheaper as compared with others [4].

\section{SYSTEM COMPOSITION}

The system explained in this research paper is a stand alone system consisting of following individual systems:-

1) Generating a DC signal by using a suitable photovoltaic tracking system.

2) Stepping up of generated DC signal by using an appropriate boost converter.

3) Conversion of DC signal to AC signal using a single phase bridge inverter circuit with proper filter.

Fig.1 shows a simlink model of a photovoltaic module. It is assumed that the average insulation is $1000 \mathrm{watt} / \mathrm{m}^{2}$.The PV module parameters considered are open circuit voltage(Voc),short circuit current(Isc) and rated current i.e $\mathrm{PV}$ current at maximum power point and rated voltage under standard test condition. 


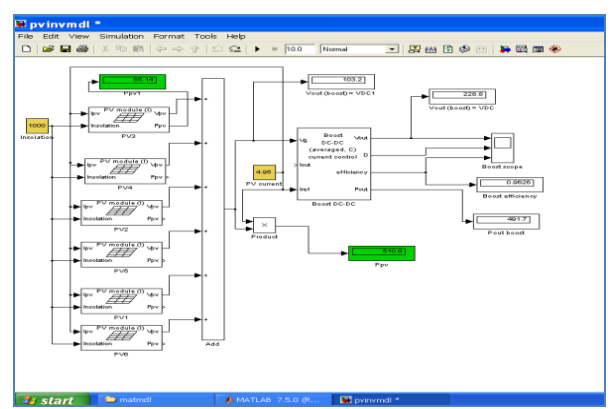

Fig.1

\section{BOOST CONVERTER}

In boost converter the output DC voltage is greater than the input voltage [17].This can be achieved by considering the following theoretical approach for the circuit shown in Fig.2. This circuit uses power MOSFETs which can be used to step up the voltage.

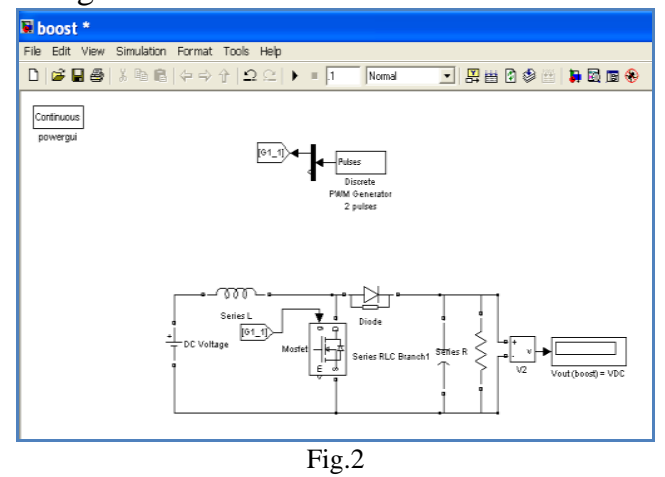

The circuit operation can be divided into two modes:-

Mode1:- When transistor Q1 is switched $\mathrm{ON}$ at $\mathrm{t}=0$

Mode2:- When transistor Q1 is switched OFF at $\mathrm{t}=\mathrm{t}_{1}$

When transistor Q1 is switched ON, the input current rises and flows through inductor L and Q1 as shown in Fig.3.

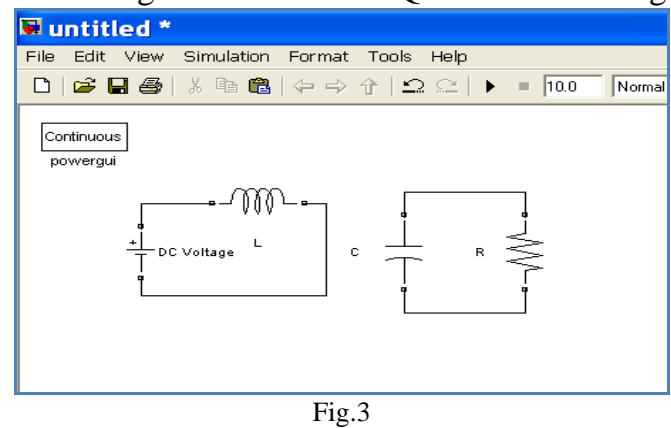

When Q1 is switched OFF, the current flows through L, C, load and diode $\mathrm{D}_{\mathrm{m}}$ as shown in Fig.4.

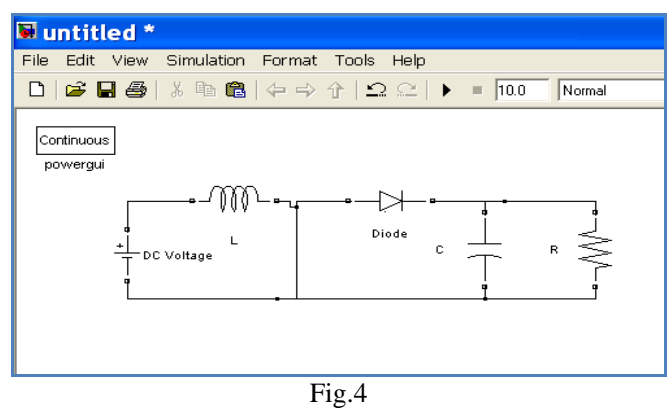

Assuming that inductor current rises linearly from $\mathrm{I}_{1}$ to $\mathrm{I}_{2}$ in time $t_{1}$, then the input voltage $\mathrm{Vs}$ is given by

$$
\begin{gathered}
V s=L \frac{I_{2}-I_{1}}{t_{1}}=L \frac{\Delta_{I}}{V s} \\
t_{1}=L \frac{\Delta_{I}}{V s} \\
\Delta_{I}=\frac{V s}{L} t_{1}
\end{gathered}
$$

If the inductor current falls linearly from I 2 to I 1 in time t2 then

Also

$$
V s-V a=L \frac{I_{1}-I_{2}}{t_{2}}=-L \frac{I_{2}-I_{1}}{t_{2}}
$$

$$
\begin{aligned}
& V s-V a=-L \frac{\Delta_{I}}{t_{2}} \\
\Delta_{I}= & \frac{-(V s-V a)}{L} t_{2}
\end{aligned}
$$

where $\Delta_{\mathrm{I}}$ is the peak to peak ripple current of inductor $\mathrm{L}$ and $\mathrm{Va}$ is the average output voltage.

Thus equation 1 and 2 can be equated as

$$
\begin{aligned}
& \frac{V s .}{L} t_{1}=\frac{-(V s-V a)}{L} t_{2} \\
& V s . t_{1}=-(V s-V a) t_{2}
\end{aligned}
$$

Considering $\mathrm{t}_{1}=\mathrm{Kt}$ and $\mathrm{t} 2=\mathrm{T}(1-\mathrm{k})$

$$
\begin{gathered}
V s . K T=-(V s-V a) t(1-K) \\
V s . K=-(V s-V a)(1-K) \\
V s . K=-V s(1-K)+V a(1-K) \\
V s(K+1-K)=V a(1-K) \\
\frac{V s}{V a}=(1-K)
\end{gathered}
$$

Assuming lossless circuit

$$
\text { ls }=\frac{l a}{(1-K)}
$$

For frequency substituting $\mathrm{K}=\mathrm{t}_{1} / \mathrm{t}$

$$
t_{1}=\frac{V a-V s}{V a \cdot f}
$$

Switching period t can be calculated as

$$
\begin{gathered}
t=\frac{1}{f}=t_{1}+t_{2} \\
=\Delta_{I} \frac{L}{V s}+\frac{\Delta_{I}}{(V a-V s)} \cdot L \\
=\frac{\Delta_{I} L(V a-V s)+\Delta_{I} \cdot L \cdot V s}{V s(V a-V s)}
\end{gathered}
$$

Thus

$$
t=\frac{1}{f}=\Delta_{I} L \frac{V a}{V s(V a-V s)}
$$

Thus peak to peak ripple current is given by

$$
\Delta_{I}=\frac{V s(V a-V s)}{f \cdot L \cdot V a}=\frac{V s . K}{f L}
$$

When transistor is ON the capacitor supplies load current for $t=t_{1}$. Thus the average capacitor current during time $t_{1}$ is $I_{c}=I_{a}$ and peak to peak ripple voltage of capacitor is

$$
\begin{gathered}
\Delta V c=V c-V c_{(t=0)} \\
=\frac{1}{C} \int_{0}^{t_{1}} I c \cdot d t \\
=\frac{1}{C} \int_{0}^{t_{1}} I a \cdot d t=\frac{1}{C} \cdot I a \cdot t_{1}
\end{gathered}
$$

Thus

But

$$
\Delta V c=I a \cdot \frac{t_{1}}{C}
$$

$$
t_{1}=\frac{V a-V s}{V a \cdot f}
$$


Therefore

$$
\begin{aligned}
\Delta V c & =\frac{V a(V a-V g)}{V a \cdot f \cdot C} \\
\Delta V c & =I a \cdot \frac{K}{f \cdot C}
\end{aligned}
$$

If $\mathrm{I}_{1}$ is the average inductor current, the ripple current is $\Delta I=2 I_{1}$

$$
\begin{gathered}
\frac{V s \times K}{f L}=2 I_{1}=2 I a=\frac{2 V s}{(1-k) R} \\
L c=L=\frac{K(1-K) R}{2 f}
\end{gathered}
$$

If $t_{1}$ is the average capacitor voltage, then capacitor ripple voltage is $\Delta V c=2 V a$

$$
\text { Thus } \quad 2 V a=I a \cdot \frac{K}{f c}=2 I a \mathrm{R}
$$

The value of capacitor is calculated as $C=\frac{K}{2 f R}$

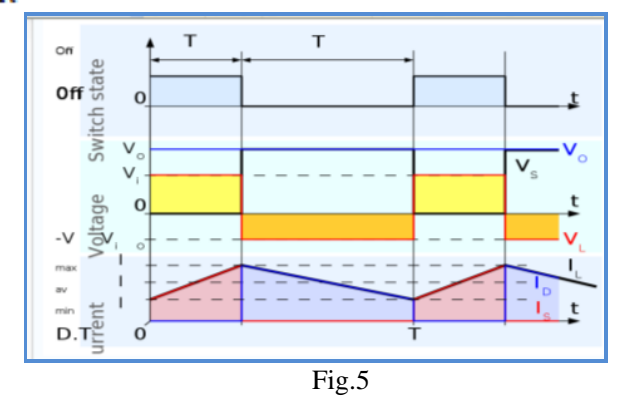

\section{Inverter Model}

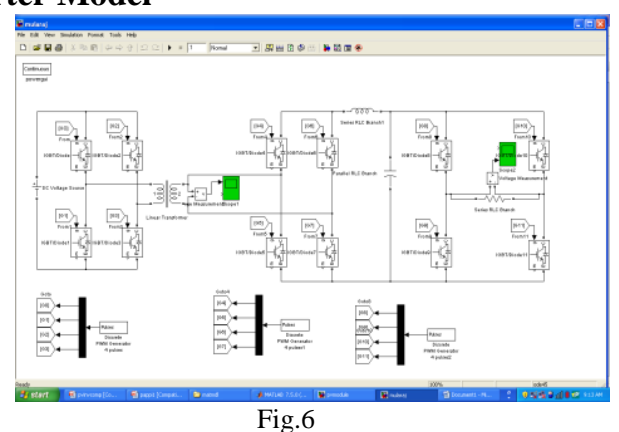

The inverter model used for simulation is a pulse width modulated inverter as shown in Fig.6.In such type of inverter, the input DC voltage from a solar tracker or battery which is constant in magnitude, is applied to the inverter circuit. The inverter circuit consists of switching devices such as IGBT, MOSFET which rectifies the output voltage. Thus the inverter must control the magnitude and frequency of the generated AC signal. This is achieved by using pwm technique. The type of switching used in model is unipolar switching. In pawn with unipolar switching; the two legs of full bridge inverter are not switched simultaneously. The two legs are controlled separately by comparing the modulating signal (Vmod) and carrier signal (Vref).

1) If $\mathrm{Vmod}>\mathrm{Vref}$ then G1is $\mathrm{ON}$ and $\mathrm{Vo}=\mathrm{Van}$

2) If $\mathrm{Vmod}<\mathrm{Vref}$ then $\mathrm{G} 2$ is $\mathrm{ON}$ and $\mathrm{Vo}=0$

3) If $-\mathrm{Vmod}>\mathrm{Vref}$ then G3 is $\mathrm{ON}$ and $\mathrm{Vo}=\mathrm{Vbn}$

If $-\mathrm{Vmod}<\mathrm{Vref}$ then $\mathrm{G} 4$ is $\mathrm{ON}$ and $\mathrm{Vo}_{\mathrm{O}}=0$

$$
\mathrm{VO}=\mathrm{Van}-\mathrm{Vbn}
$$

Thus G1 and G4 is ON, Van=Vd, Vbn=0 then $\mathrm{Vo}=\mathrm{Vd}$

$\mathrm{G} 2$ and $\mathrm{G} 3$ is $\mathrm{ON}, \mathrm{Van}=0, \mathrm{Vbn}=\mathrm{Vd}$ then $\mathrm{Vo}=-\mathrm{Vd}$

$\mathrm{G} 1$ and $\mathrm{G} 3$ is $\mathrm{ON}, \mathrm{Van}=0, \mathrm{Vbn}=0$ then $\mathrm{VO}=0$

$\mathrm{G} 2$ and $\mathrm{G} 4$ is $\mathrm{ON}, \mathrm{Van}=0, \mathrm{Vbn}=0$ then $\mathrm{VO}=0$
Thus when switching occurs, the output voltage changes between 0 and $+\mathrm{Vd}$ as well as 0 and $-\mathrm{Vd}$ voltage levels. This is called as unipolar switching. The unipolar switching has advantage of doubling the switching frequency which results in cancellation of harmonics.

\section{Simulation Result}

The performance of photovoltaic inverter was tested using MATLAB and the output signal was observed with different carrier frequencies.

\section{1) Analysis of photovoltaic model}

Insolation $=1000 \mathrm{w} / \mathrm{m} 2$

Ratings of PV cell

(With bypass diode)

Voc $=22.2$ volts, Isc $=5.45 \mathrm{Amp}$

Voltage at Pmax $=17.2$ volts,

Current at Pmax $=4.95$ Amp

Output dc voltage $=103.2$ volts

\section{2) Analysis of boost converter}

Input dc voltage $=103.2$ volts

Inductance $(\mathrm{L})=2 \mathrm{mH}$

Load Resistance $(\mathrm{Rl})=2 \mathrm{~K}$

Output dc Voltage $=235.6$

\section{3) Analysis of Inverter model}

PWM Generation:-

Sampling Time $=2 \mu \mathrm{sec}$

Modulating Signal:- Modulation Index $=0.8$

Frequency $=60 \mathrm{~Hz}$

Input de signal $=235.6$

\section{OUtPut SIGNAL}

Carrier Frequency $=1.5 \mathrm{KHz}$

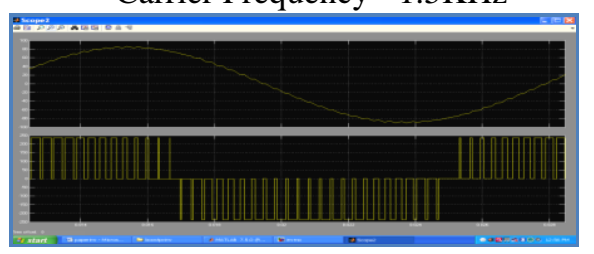

Carrier Frequency $=2.5 \mathrm{KHz}$

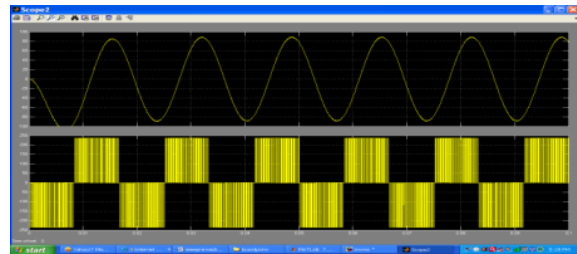

Carrier Frequency $=10 \mathrm{KHz}$

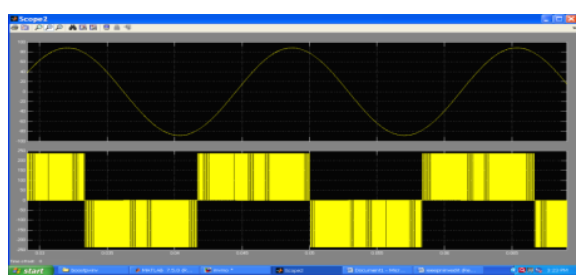

\section{HARDWARE IMPLEMENTATION}

A photovoltaic bidirectional link inverter was implemented using a solar tracker.An inverter circuit with a 
filter, driver circuit with processor tms320c28027 was developed and tested with a conventional solar tracker.The specification of hardware is as follows:-

Specification of PV module

Model - SLP5-12, Rated Power: - 5watt

Rated Voltage:-17volt, Rated Current:-0.29 Amp

O.C voltage: - 21.6 volts, S.C current: - 0.34 Amp

Slandered Test Condition - 1000watt $/ \mathrm{m}^{2}$

Battery specification

Microtek: - 12 volt, 7.2Ah

Inverter circuit specification

IGBT Driver: - TLP 250

IGBT: - G4PC60U

Filter Circuit: - Inductor-10mH, Resistance - 22 ohms, Capacitor - 22 microfarad

A solar tracker as shown in Fig.7 was designed to charge a 12 volt, 7 amp battery. The solar tracker was able to track the sun from east to west based on the LDR circuit by rotating the PV module with 22.5 degree at every 3 hours to get maximum power.

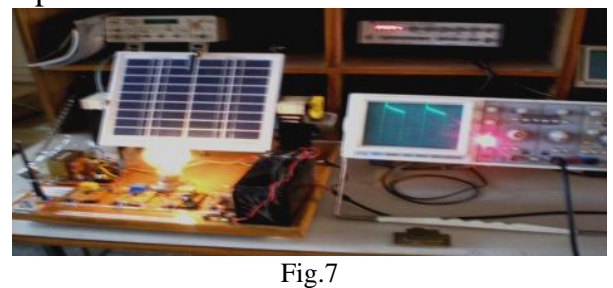

A bidirectional high frequency link inverter was developed with the given specification in order to achieve relatively small size, light weight and high efficiency inverter circuit as shown in Fig. 8

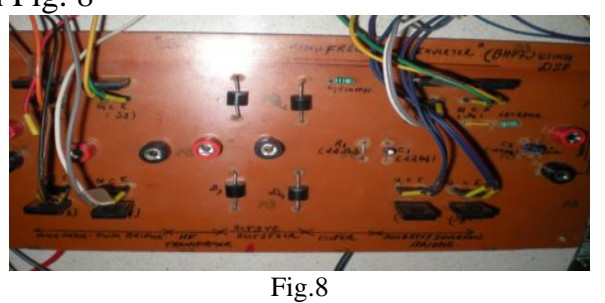

For switching of the IGBT's a driver circuit based on TLP250 was used with processor TMS320C28027 as shown in Fig.9 and the output signal was observed.

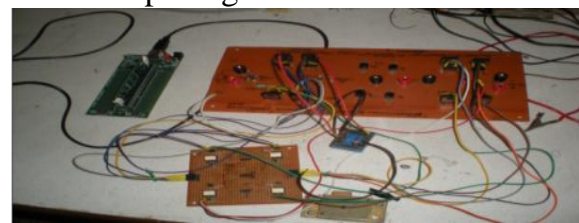

Fig.9

\section{OUTPUT SignAls OBSERVED}

\section{PWM Signal:-}

PWM signal for switching of IGBT was generated from a driver circuit consisting of IC TLP250.The input to driver circuit was given from the GPIO 1 to GPIO4 pins of processor TMS320C28027.The PWM signal through TMS320C28027 was generated by loading, debugging and building the program in code composer studio(version 3.1). The PWM signal generated is shown in fig. 10.

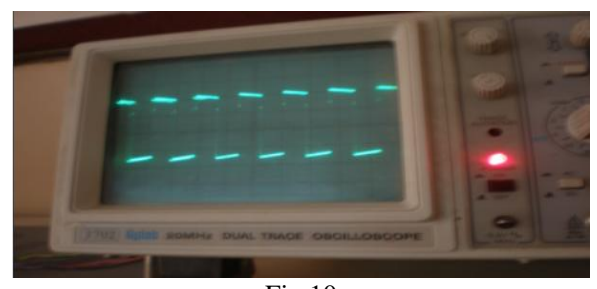

Fig.10

Finally the generated PWM signals were applied to the IGBT's of the inverter circuit and the output AC signal was observed at the output of filter circuit. The fig. 11 shows the generated AC signal.

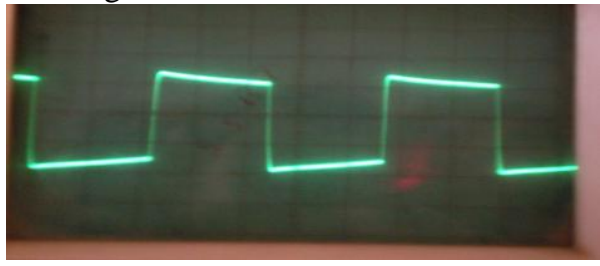

Fig. 11

\section{CONCLUSION}

This paper presents the simulation and hardware of a single phase photovoltaic inverter using TMS320C28027 control. It is observed in simulation that with the increase in frequencies the nature of the ac signal can be improved.Further,the implementation of TMS320C28027 processor makes the inverter more flexible due to its real time analysis. Also by considering a conventional photovoltaic tracking system maximum power can be extracted.

\section{REFERENCES}

[1] Dezso Sera, Remus Teodorescu, Tamas Kerekes Teaching Maximum Power Point Trackers Using a Photovoltaic Array Model with Graphical User Interface

[2] Tamás Kerekes, Dezső Séra, Remus Teodorescu 'PV inverter control using a TMS320F2812 DSP'IEEE Transaction.

[3] A. Yafaoui., B. Wu and R. Cheung, "IMPlEMENTATION OF MAXIMUM POWER POINT TRACKING ALGORITHM FOR RESIDENTIAL PHOTOVOLTAIC SYSTEMS", 2nd Canadian Solar Buildings Conference Calgary, June 10 - 14, 2007

[4] Giuseppe Fedele,Domenico Franscino, "Spectral analysis of a class of DC-AC PWM inverters by Kepteyn Series" IEEE Transaction on power electronics,vol. 25,No. 4,April 2010,pg.839-849.

[5] www.ti.com

[6] Hao Zhou,Chawan Tong,Meiqin Mao,Chan Gao, "Development of single phase photovoltaic grid connected inverter based on DSP control" $2^{\text {nd }}$ International Symphosium on power electronics for distributed generation system,2010,pg.no.650-653

[7] Bo Yang,Wuhua Li,Yi Zao,Xiangning He, "Design \& analysis of grid connected photovoltaic system" IEEE transaction on power electronics,vol.25,no.4,April 2010,pg.992-1000.

[8] Zhilei Yao,Lan Xio,Yanggang Yan, "Seamless Transfer of single phase grid interactive inverters between grid connected \& stand alone modes" IEEE transaction on power electronics,vol. 25,No. 6,June2010, pg.1597-1603.

[9] M.Chael,E.Ropp \& Sigifredo Gonzalez "Development of a MATLAB/simlink model of a single phase grid connected photovoltaic system" IEEE transaction on Energy conversion,2009,vol 3,pg 344-349,

[10] Hiren Patel,Vivek Agarwal, "A single stage single phase transformerless doubly gronded grid connected PV interface",IEEE transaction on Energy Conversion.Volume-24,no.1, march 2009.

[11] Huan-Liang Tsei,Ci-Siang Tu,Yi-Jiesu, "Development of generalized photovoltaic model using MATLAB/simulink",proceedings of the world congress on engineering \& computer science,2008,WCECS, oct2008,san Francisco,USA. 
[12] D.Amorndecaphon \& S.Prenurudeeppreechacharn, “An improved single phase inverter for small PV system using soft switching technique,proceeding of ECTI-CON2008.

[13] Feel-Soon Kang,Sung-Jun Park,Chel-U Kim, "Multilevel PWM inverters suitable for the use of stand alone photovoltaic power system.",IEEE transaction on energy conversion,vol.20.no. 4, Dec2005, pg 906-915.

[14] [Zhao Qinglin,Xu Yunhua,Jin Xiaoyi,Wu Weiyang, "DSP based closed loop control of bidirectional high frequency link inverter with active clamp",IAS 2005,IEEE proceedings,pg. -928-933.

[15] Ovidiu pop,Gabrel Chindris,Andri Dulf, "using DSP technology for true sine PWM inverters", $27^{\text {th }}$ International Spring Seminar on Electronics Technology,2004,IEEE,pg 141-146.

[16] T.J.Liang,J.F.Chen,C.A.Cheng, "Study and implementation of DSP based photovoltaic energy conversion system",IEEE proceedings , PEDS2001,pg 807-810.

[17] Mohan, Undeland, Riobbins'Power Electronics-Converters, Applications \& Designs' Media Enhanced Third Edition, Wiley-India Edition, 2008.

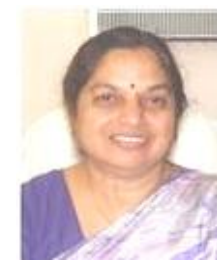

Saroj Rangnekar, is Professor \& head in the Department of Energy, Energy Centre at Maulana Azad National Institute of Technology, Bhopal, India. She has 32 years of teaching \& research experience and received three National awards. She has published 85 papers in various International and National journals, conference proceedings, and participated in International conferences in India, UK, USA and Switzerland.

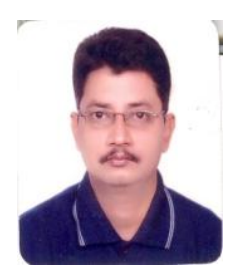

Prashant.V.Thakre, is a Ph.D. research scholar in the Department of Energy at Maulana Azad National Institute of Technology, Bhopal, India \& working as Assistant Professor in E\&TC at SSBT's College of Engineering \& Technology, Jal

gaon. He has 14 years teaching experience and 05 publications in various National, International conferences \& Journals. His research area is photovoltaic inverter. 